\title{
Very broadband strain-rate measurements along a submarine fiber-optic cable off Cape Muroto, Nankai subduction zone, Japan
}

\author{
Satoshi Ide ${ }^{1^{*}}\left(\mathbb{D}\right.$, Eiichiro Araki $^{2}$ and Hiroyuki Matsumoto ${ }^{2}$
}

\begin{abstract}
Distributed acoustic sensing (DAS) is a new method that measures the strain change along a fiber-optic cable and has emerged as a promising geophysical application across a wide range of research and monitoring. Here we present the results of DAS observations from a submarine cable offshore Cape Muroto, Nankai subduction zone, western Japan. The observed signal amplitude varies widely among the DAS channels, even over short distances of only $100 \mathrm{~m}$, which is likely attributed to the differences in cable-seafloor coupling due to complex bathymetry along the cable route. Nevertheless, the noise levels at the well-coupled channels of DAS are almost comparable to those observed at nearby permanent ocean-bottom seismometers, suggesting that the cable has the ability to detect nearby micro earthquakes and even tectonic tremors. Many earthquakes were observed during the 5-day observation period, with the minimum and maximum detectable events being a local M1.1 event 30-50 km from the cable and a teleseismic Mw7.7 event that occurred in Cuba, respectively. Temperature appears to exert a greater control on the DAS signal than real strain in the quasi-static, sub-seismic range, where we can regard our DAS record as distributed temperature sensing (DTS) record, and detected many rapid temperature change events migrating along the cable: a small number of large migration events (up to $10 \mathrm{~km}$ in $6 \mathrm{~h}$ ) associated with rapid temperature decreases, and many small-scale events (both rising and falling temperatures). These events may reflect oceanic internal surface waves and deep-ocean water mixing processes that are the result of ocean current-tidal interactions along an irregular seafloor boundary.
\end{abstract}

Keywords: Distributed Acoustic Sensing (DAS), Submarine cable, Earthquakes, Broadband, Strain, Temperature, Ocean current, Tide, Mixing processes

\section{Introduction}

Distributed acoustic sensing (DAS) is a new geophysical imaging technique that measures the ground strain (or strain rate) along a fiber-optic cable, using variations in the phase-coherent Rayleigh backscattering that are generated by a sequence of laser pulses (e.g.,Hartog 2017; Miah and Potter 2017; Lu et al. 2019; Lindsey et al. 2020). Although DAS was originally developed for the oil and gas industry, it has since been utilized to address a wide

\footnotetext{
*Correspondence: ide@eps.s.u-tokyo.ac.jp

${ }^{1}$ Department of Earth and Planetary Science, The University of Tokyo,

7-3-1, Hongo, Bunkyo, Tokyo 113-0033, Japan

Full list of author information is available at the end of the article
}

range of seismological research topics (e.g., Zhan 2020). It is a relatively inexpensive way to obtain spatially dense and temporally continuous measurements, when we can use fiber-optic cables that have already been installed for communication purposes. We can simultaneously measure the strain at many locations along the cable (meterscale intervals) at a high-sampling rate $(\sim 1000$ samples per second (sps)) by simply connecting an interrogator, which is a laser transmitter/receiver system, to one end of the cable. It has been reported that the noise levels of the strain measurements are sufficiently small to detect natural earthquakes (Lindsey et al. 2017). Wang et al. (2018) have demonstrated the similarity between DAS and seismograph strain measurements, and confirmed 
that the observed signal is axial strain along a fiber-optic cable in the ordinary frequency range for seismic observations (i.e., several Hertz). At lower frequencies, AjoFranklin et al. (2019) observed the surface waves from large teleseismic earthquakes, and Lindsey et al. (2020) demonstrated how to convert DAS records into broadband seismograms via a comparative analysis of DAS and seismometer signals in 1-120 s range. Further applications for subsurface structural investigations have been proposed, such as receiver function (Yu et al. 2019) and $\mathrm{H} / \mathrm{V}$ spectral ratio (Spica et al. 2020a) analyses.

Ocean-bottom strain measurements are a promising research direction for future DAS observations since the installation of conventional geophysical sensors is difficult, and several studies have successfully installed DAS interrogators along submarine communication cables. Williams et al. (2019) used a telecommunication cable at shallow $(<40 \mathrm{~m})$ depths offshore Belgium, and analyzed the spectral features of the ambient DAS signals. These signals mostly consisted of ocean surface gravity waves and Scholte waves, which reflect solid earth-ocean coupling. They also observed the seismic waves from a large (Mw 8.2) teleseismic (hypocentral distance of $\sim 150^{\circ}$ ) earthquake, although no regional earthquakes were recorded due to the low seismicity. Sladen et al. (2019) also utilized a telecommunication cable offshore France for DAS observations to detect a small (M1.9) earthquake that occurred $\sim 100 \mathrm{~km}$ from the cable. Shinohara et al. (2019) and Spica et al. (2020b) used a fiber-optic cable that was originally installed for ocean-bottom seismic sensors to monitor active seismicity offshore Tohoku region, Japan. In addition to observation of many small earthquakes, they showed that DAS observations could potentially resolve spatial heterogeneities in the very shallow seismic structure along the cable. Some ocean sediments possess shear-wave ( $\mathrm{S}$-wave) velocities as low as $300 \mathrm{~m} / \mathrm{s}$.

Here we used a fiber-optic cable that was originally used for ocean-bottom seismic observations off Cape Muroto, Nankai subduction zone, where the Philippine Sea Plate is subducting beneath western Japan at $3-5 \mathrm{~cm} /$ years. Many large $(M 8+)$ historical earthquakes have occurred in this region at 100-200-year intervals; more than 70 years have now passed since the last large event, the 1946 Nankai Earthquake; therefore, various observation instruments have been installed in this region with the hope of obtaining comprehensive observations of the next expected large earthquake. Our fiber-optic cable was a part of such observation systems. Although the ambient seismicity in this region is low compared with other regions in Japan, various types of slow earthquake (e.g., Beroza and Ide 2011; Obara and Kato 2016), such as slow slip events and tectonic tremors, occur frequently in the region. The relationship between slow and large megathrust earthquakes is of great interests and the effectiveness of DAS observations in detecting such phenomena is important to evaluate. Our temporary observations confirm the feasibility of acquiring DAS observations for earthquake detection and analysis. Furthermore, we also demonstrate the potential to investigate deepocean water movement via DAS observations, since these observations mainly record temperature changes in the quasi-static, sub-seismic frequency range.

\section{DAS observations and noise levels}

The Japan Agency for Marine Earth Science and Technology (JAMSTEC) developed the Comprehensive Seafloor Monitoring System off Cape Muroto in 1997 (Momma et al. 1997). A submarine cable with six single-mode fibers connects the land station and ocean-bottom instruments (Fig. 1). The total cable length is $120 \mathrm{~km}$, with two ocean-bottom seismometers deployed 70 and $100 \mathrm{~km}$ from the coast. The system was operated for more than 20 years before being ceased in 2019. The cable was not covered by sediments, except for a $2-\mathrm{km}$ shallow section, at the time of installation; however, the current status of the seafloor cable is unknown. We used a $50-\mathrm{km}$ section of the cable that extended from the coast for the DAS observation. No instruments are attached to this section. Figure 1 shows the regional bathymetry and estimated cable route. The bathymetry is complex in this region, and the cable extends to the south, passing across the edge of Muroto Basin and over Tosabae Ridge.

We acquired temporary DAS observations during the January 27-31, 2020 (JST) period along this cable. The DAS system was a commercial product of AP Sensing (model N5200A) with the maximum measurement fiber length of $50 \mathrm{~km}$. The DAS system is based on phasebased C-OTDR in $1550 \mathrm{~nm}$ wavelength class 1 laser, together with telecommunication grade low attenuation single mode fiber used in this experiment, allowing measurement of Rayleigh scattered waves from such a long distance. We used several different parameter settings. The most used parameter settings for our observations were a 500 -sps temporal sampling rate, $5.10-\mathrm{m}$ spatial sampling interval, and 40.4-m gauge length. There were 9788 channels in the $50-\mathrm{km}$ section of cable. The size of the uncompressed records was $\sim 1 \mathrm{~TB} /$ day, since the interrogator measured a 16-bit recording of the differential strain (strain rate) at each channel.

The sensitivity of the 9788 channels to ground strain varied along the cable. Some channels recorded almost nothing, even when clear seismic signals were recorded at other channels. These insensitive channels recorded low levels of ambient noise that corresponded to microseisms, which are discussed later in the text. 


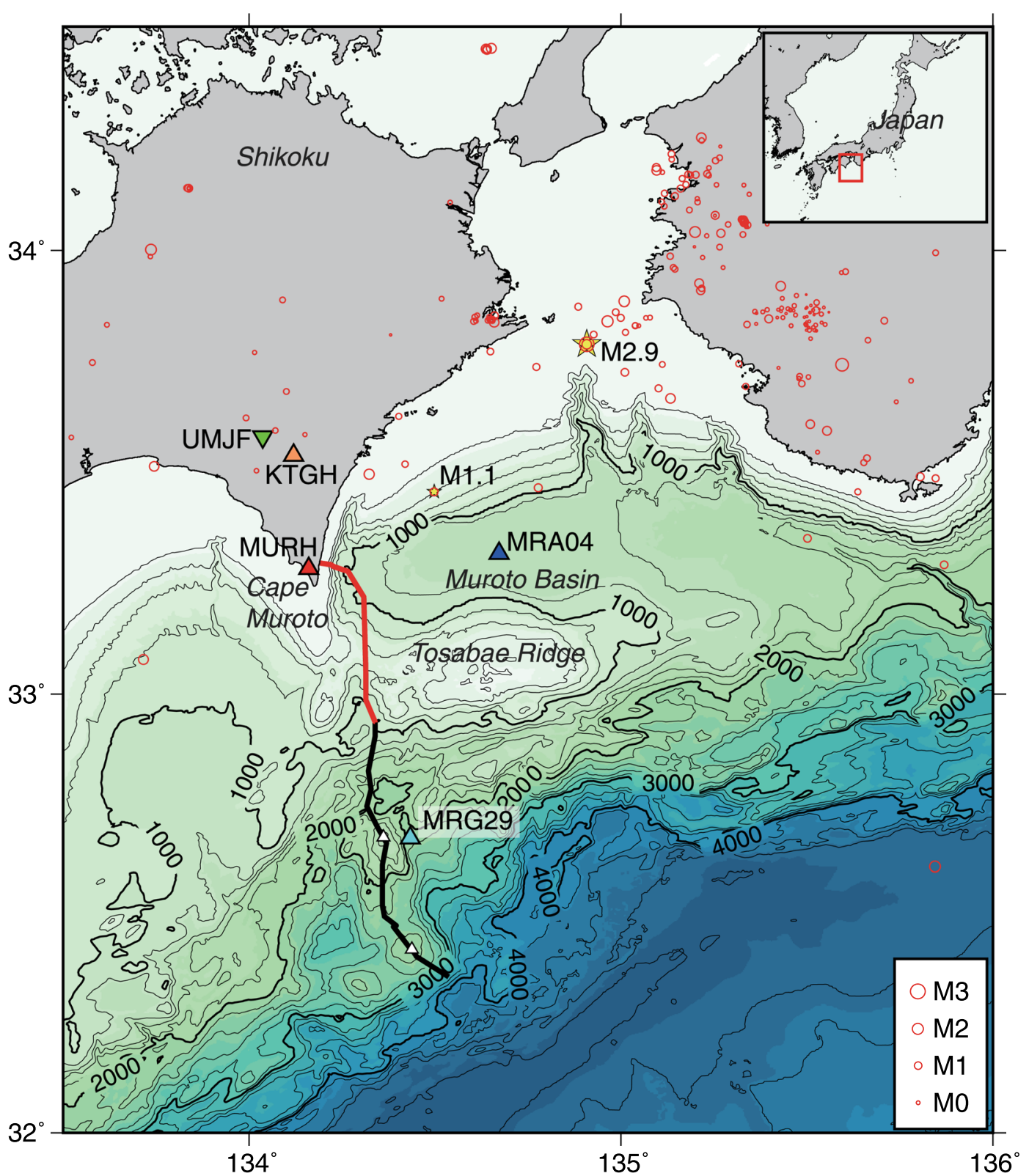

Fig. 1 Locations of the seafloor fiber-optic cable and hypocenter distribution during the observation period. The bold line represents the cable route of the Comprehensive Seafloor Monitoring System off Cape Muroto, with the red section indicating the 50-km-long DAS observation section. The two small open triangles along the cable show the ocean-bottom seismometer locations. The triangles with different colors are the stations that were used for a comparison with the DAS observations: MURH and KTGH (Hi-net), UMJF (F-net), and MRA04 and MRG29 (DONET2). Red circles indicate the epicenters of earthquakes that occurred during the January 27-31, 2020 (JST), period, as determined by the Japan Meteorological Agency

We computed the standard deviation of the strain rate using a 5 -min interval for the entire observation period to visualize the spatial heterogeneity of the channel sensitivity. Figure 2 shows the median values of the standard deviations for the entire observation period. The insensitive channels are those with very small standard deviations, which are supposed to be "uncoupled" from the ocean bottom. The observed amplitudes at channels $0-500$ (first $2.5 \mathrm{~km}$ of cable from the coast) were often near the maximum of the dynamic range $(-\pi$ to $\pi$ in phase), and were likely saturated due to the skipping of some cycles by large noise, which made the analysis difficult. At channels 500-2200, the standard deviations were generally small with the exception of 


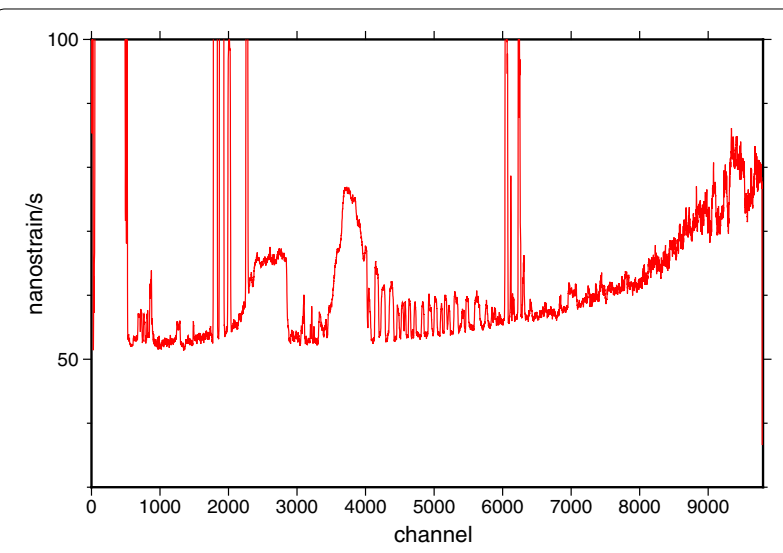

Fig. 2 Standard deviation of observation at each channel. Median values of standard deviation of strain rate, measured for each 5-minute at each channels some channels, suggesting weak coupling. There were two sections with large standard deviations: channels 2200-3000 ( 4 km length) and channels 3500-4000 ( $2.5 \mathrm{~km}$ length). Above channel 4000, there were alternating sections of coupled and uncoupled channels. For the channels that were far from the coast, there was a smooth increase in the standard deviation with channel number. This increase likely arose from the high noise levels due to the attenuation of the laser pulses.

We selected ten channels and computed their spectrograms, which consist of periodograms of the strain rate at 5 -min intervals for the entire observation period (Additional file 1: Figure S1). Two of the ten channels (6000 and 7510) are examples of uncoupled channels, which only recorded small amplitudes during the entire observation period. Figure 3 summarizes the median of the spectral

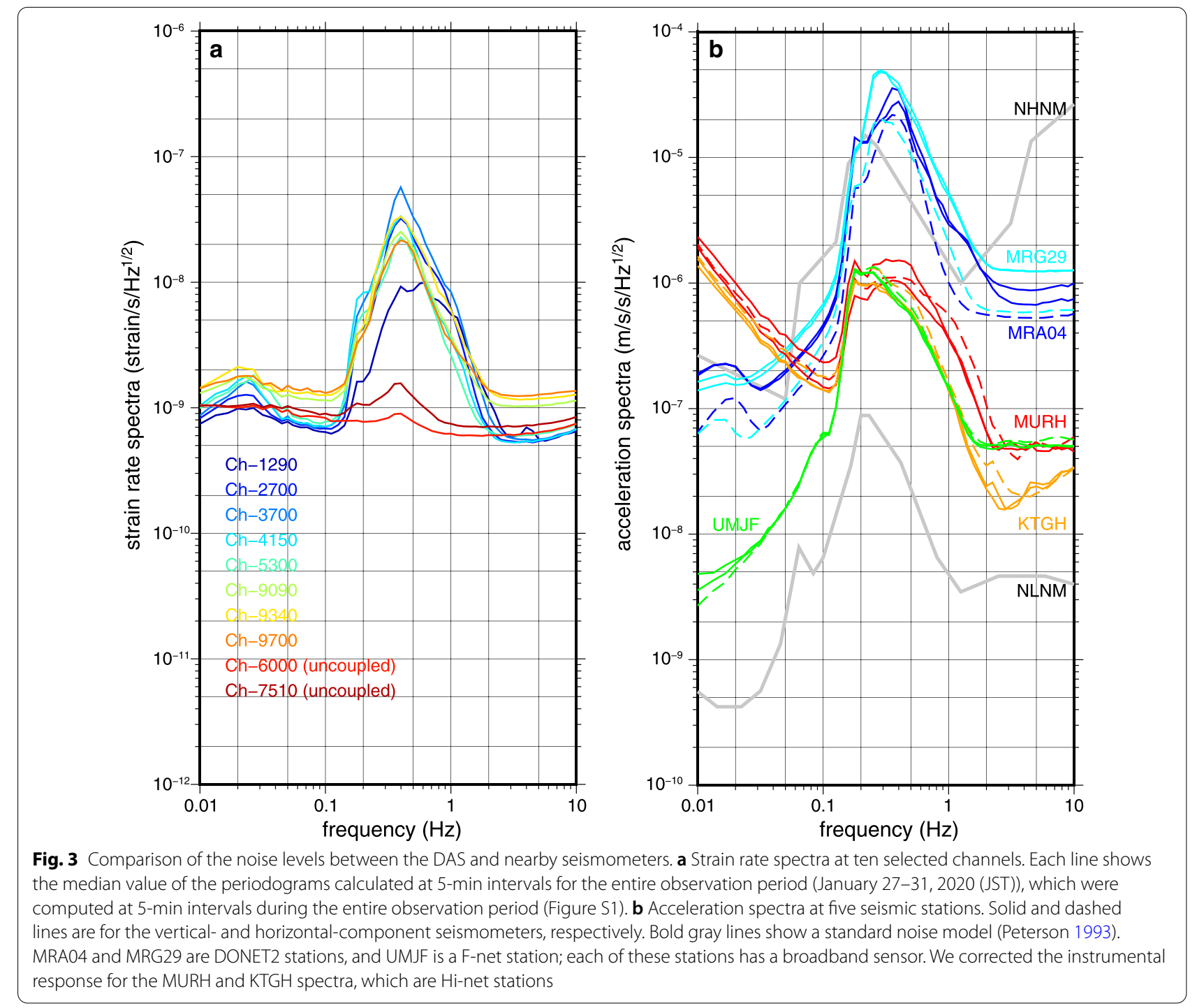


amplitude (5-min interval) for the entire observation period at these ten channels (Fig. 3a), together with the spectral amplitudes that were estimated in a similar manner using the accelerations at several nearby seismic stations (and their associated networks): MUTH and KTGH (Hi-net, a high-sensitivity seismic network with short period $(1 \mathrm{~Hz})$ sensors); UMJF (F-net, a broadband seismic network); and MRA04 and MRG29 (DONET2, an ocean-bottom network with broadband sensors) (Fig. 3b). All these seismic stations are maintained by the National Research Institute for Earth Science and Disaster Resilience, and the data are publicly available.

The amplitudes of the acceleration spectra at the two DONET2 stations are $\sim 10^{-6} \mathrm{~m} / \mathrm{s}^{2} / \mathrm{Hz}^{1 / 2}$ above $2 \mathrm{~Hz}$, whereas those of the DAS strain rate spectra are $\sim 1$ nanostrain $/ \mathrm{s} / \mathrm{Hz}^{1 / 2}$. These two levels are comparable if we assume plane waves with a velocity of $\sim 1 \mathrm{~km} / \mathrm{s}$ are producing this background noise (e.g., Benioff 1935). A peak at $0.3-0.5 \mathrm{~Hz}$ is visible in both the DONET2 and DAS observations, suggesting that similar ambient signals are being recorded above $0.1 \mathrm{~Hz}$. This peak at $0.3-0.5 \mathrm{~Hz}$ is common in broadband ocean-bottom seismic observations (e.g., Araki et al. 2004; Suetsugu and Shuobara 2014), and is also visible at a coastal Hi-net station (MURH). This peak is small at inland stations (KTGH and UMJF), and shifted to $0.2 \mathrm{~Hz}$, which is the secondary microseism peak that is commonly observed at many stations and in a standard noise model (Peterson 1993). Below $0.1 \mathrm{~Hz}$, the DAS noise levels appear to be worse than the DONET2 noise levels. At $\sim 0.05 \mathrm{~Hz}$, the DAS noise levels also appear to be worse than the Hi-net noise levels after the instrument response correction, although they are lower at $\sim 0.01 \mathrm{~Hz}$. Moreover, DAS recorded similar peaks responsible to infragravity waves at $\sim 0.02 \mathrm{~Hz}$. We therefore expect our DAS observations to be qualitatively similar to the DONET2 observations above $0.01 \mathrm{~Hz}$.

\section{Example earthquake observations}

Our DAS observations recorded several tens of earthquakes, despite relatively inactive regional seismicity (Fig. 1). Figure 4 shows three examples of observed earthquake signals. One of the most clearly recorded events was a M2.9 earthquake that occurred $\sim 100 \mathrm{~km}$ from the cable. Figure 4a shows a comparison of the strain records at three channels, with each consisting of the integrated strain rate after bandpass filtering at $2-16 \mathrm{~Hz}$. Both tiny $\mathrm{P}$ waves and large $\mathrm{S}$ waves are visible in most of the channels (Fig. 4d), with the exceptions being the uncoupled channels with small signal levels, as suggested from the differences in the ambient standard deviation of the strain rate (Fig. 2). The maximum signal amplitudes were $\sim 10$ to 50 nanostrain, with large variations among the channels. This large variation highlights the need to characterize each channel response when conducting a future quantitative analysis of these signals. The maximum amplitudes for the same event that were recorded at two DONET2 stations, MRA04 and MRG29, were $\sim 50$ and $\sim 10 \mu \mathrm{m} / \mathrm{s}$, which were located at epicentral distances of 56 and $131 \mathrm{~km}$, respectively. A relation between the $10-50$ nanostrain DAS observations and $10-50 \mu \mathrm{m} / \mathrm{s}$ ocean-bottom seismometer observation is explicable by assuming plane waves at a velocity of the order of $1 \mathrm{~km} / \mathrm{s}$, which is expected from Fig. 3.

The smallest earthquake recorded during these temporary observations was a M1.1 event that occurred $30-50 \mathrm{~km}$ from the cable (Fig. 4b). The signal was only visible at the channels with good coupling close to the source. Nevertheless, the signal-to-noise ratio was comparable with that of a nearby Hi-net station (MURH) at some channels. This similarity likely occurred because the dominant frequency of this event was $2-4 \mathrm{~Hz}$, affected by the attenuation effects along the propagation path, whereas the coastal Hi-net station had relatively high noise levels in this frequency range.

The largest earthquake we observed was a teleseismic earthquake of Mw7.7 that occurred near Cuba on January 28, 2020 (Fig. 4c). The signal was not visible at high frequencies, but was clearly visible in the spectrograms below the microseism level at most of the channels (Additional file 1: Figure S1). The surface waves were detectable for $\sim 1 \mathrm{~h}$; however, the noise level was not good compared with the broadband seismometers, and even worse than the response-corrected Hi-net records. The amplitude differences among the DAS channels were large; channel 1290, which often observed large amplitudes at high frequencies, recorded small amplitudes at

\footnotetext{
(See figure on next page.)

Fig. 4 Example earthquake signal observations. a A moderate-sized (M2.9) event on January 27, 2020, at 16:23:31.8 (UT). The observed strain at three DAS channels (top) and the horizontal velocity seismograms at two DONET2 stations (bottom) are shown; all of the waveforms have been bandpass filtered at 2-16 Hz. b A very small (M1.1) event on January 30, 2020, at 00:20:25.7 (UT). The observed strain at three DAS channels (top) and the horizontal velocity seismograms at two Hi-net stations (bottom) are shown; all of the waveforms have been bandpass filtered at 2-16 $\mathrm{Hz}$. c A teleseismic Mw7.7 event on January 28, 2020, at 19:10:24 (UT) near Cuba. The observed strain at three DAS channels (top), and the horizontal velocity seismograms at a DONET station (MRG29) and F-net station (UMJF) (bottom) are shown; all of the waveforms have been bandpass filtered at $0.01-0.1 \mathrm{~Hz}$. All of the velocity data are shown relative to the origin time of the event. $\mathbf{d}$ DAS records for all of the channels and the earthquake in a. The amplitudes are presented as the logarithm of the normalized absolute amplitude of the strain rate, and have been bandpass filtered at 2-8 $\mathrm{Hz}$
} 


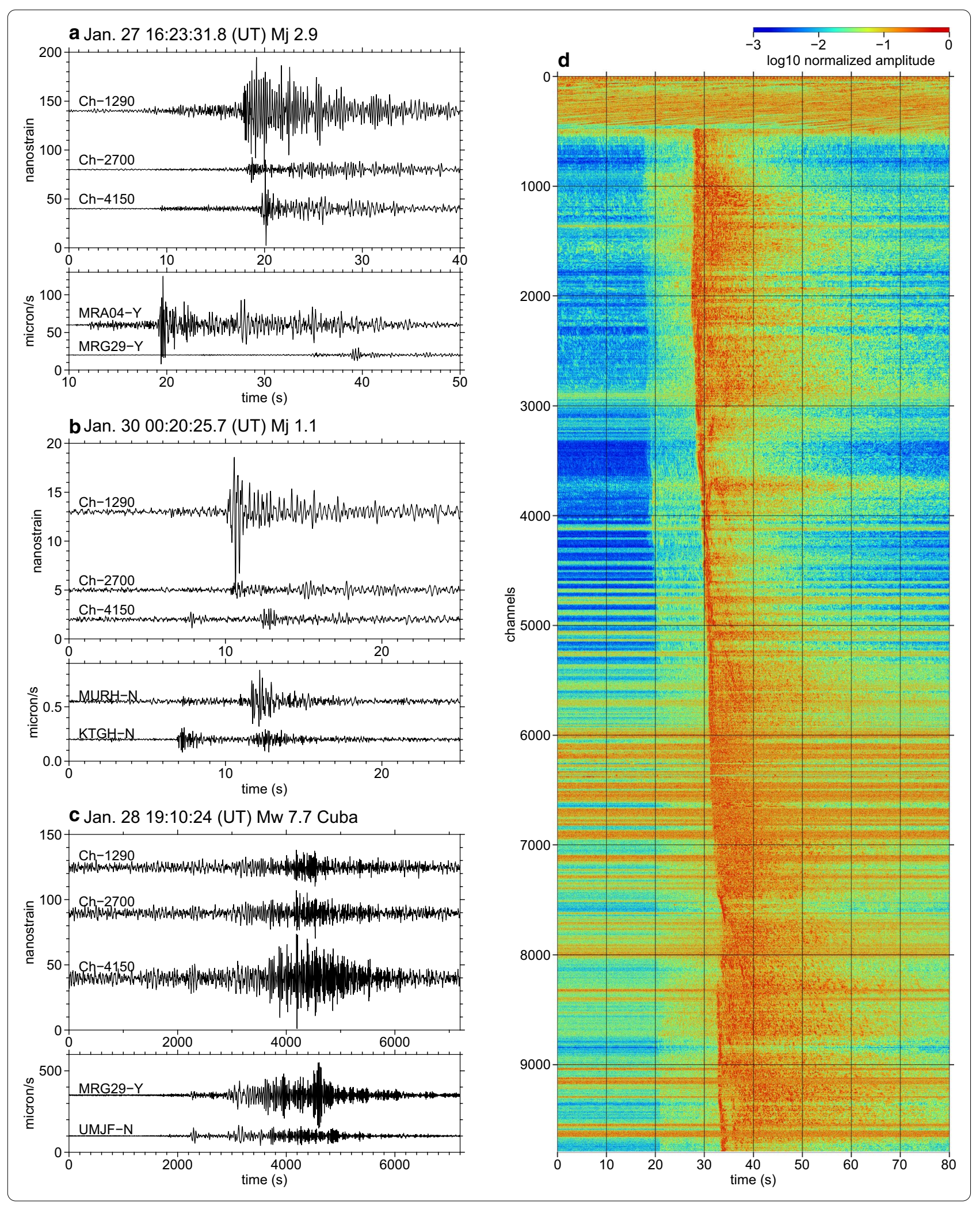


low frequencies. This again highlights the need to estimate each channel response as a function of frequency.

\section{Quasi-static observations: periodic variations and migrating events}

What can we observe using a DAS system at much lower frequencies? One may expect that the DAS observations would detect the tidal strain due to solid earth and ocean tides, since the DAS measures strain. Figure 5 shows the extremely low-frequency DAS records, with the mean strain rate measured at a 5-min interval over the entire observation period for all of the channels along the cable. We observed large spatial and temporal variations in the average strain rate above channel 1000 . The observed variation at channels $1000-4000$ exhibited a nearly daily cycle with an amplitude on the order of 0.1 nanostrain/s $\left(10^{-10} \mathrm{strain} / \mathrm{s}\right)$; this is very large since the tidal deformation of the Earth's surface is on the order of $10^{-12}$

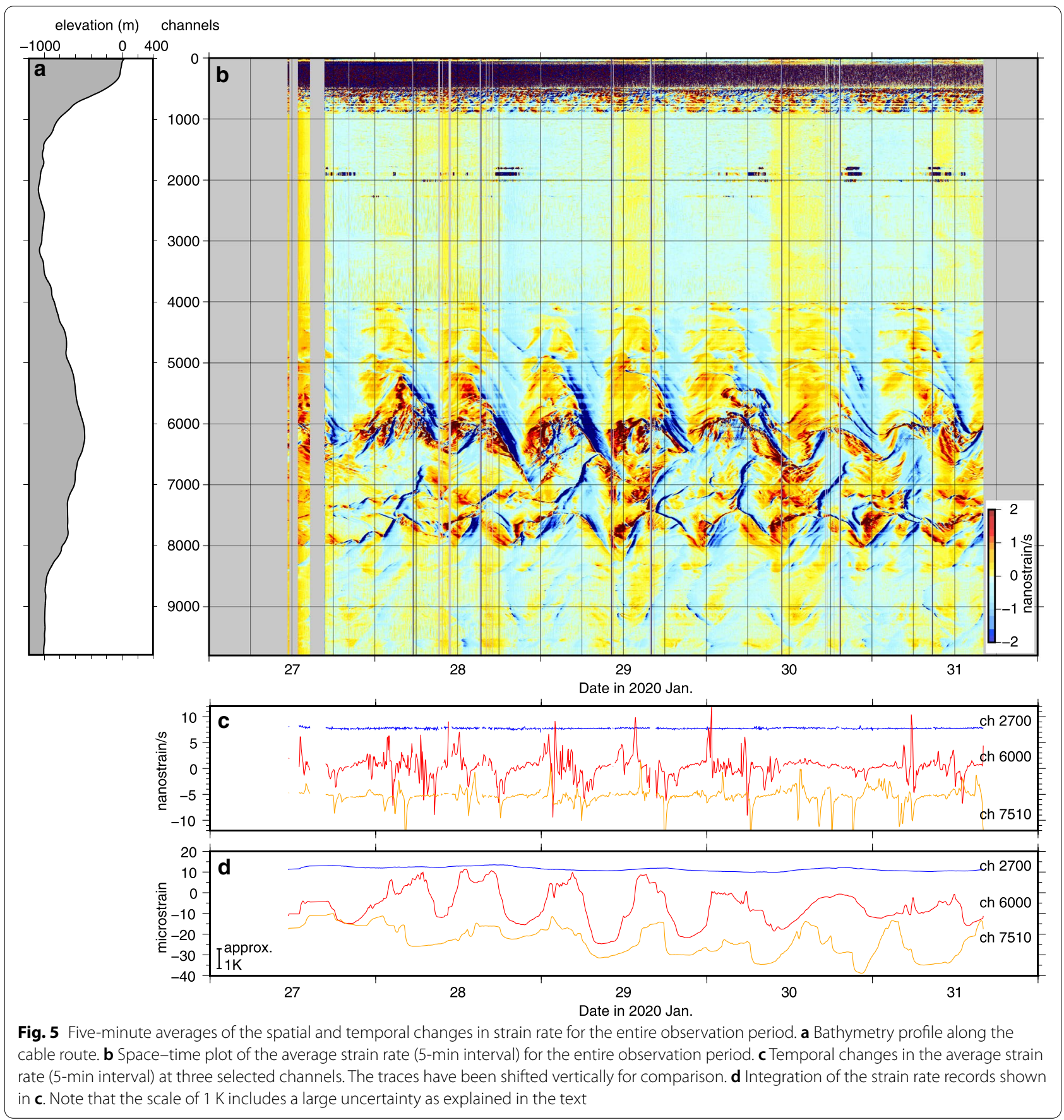


strain/s. Noticeable variations were observed at channels 4000-8000, where the cable passes the Tosabae Ridge, and similar but smaller amplitude changes occurred above channel 8000 . Temporal integration yields strain variations of $>20$ microstrain, which cannot be explained by tidal deformation. Nevertheless, the spectrum of these changes shows clear peaks that correspond to diurnal and semidiurnal tidal periods (Figure S2). The very large change at around channel 6000 has a clear 12.4-h peak, which corresponds to the M2 constituent of the tidal signal. Therefore, these variations are obviously controlled by ocean tides.

The rapid change in strain rate migrated a long distance along the cable above channel 4000 . Some large migrations of a negative anomaly propagated $\sim 10 \mathrm{~km}(2000$ channels) in $\sim 6 \mathrm{~h}$, and many small-scale migrations occurred repeatedly across many of the channels. The migration direction appears to be related to the geometry of the cable. Each of the negative anomalies propagated from the lower to higher elevations on both sides of Tosabae Ridge. Some large migrations, such as the events during the afternoon of January 28th and on the morning of January 29th, propagated over the summit of the ridge and continued further southward. The positive anomaly also migrated, but the migration speed was variable and behaved more randomly than those of the positive anomalies, which suggests that antisymmetric mechanisms influence the strain rate.

Although we have explained this change as a strain rate, the observed deformation is likely not an actual physical variation in the length of the fiber-optic cable, but rather a change in the refractive index of the fiber-optic cable due to variations in the ocean-bottom water temperature. The observed strain $\in$ depends on the temperature $T$, thermal expansion coefficient $\alpha$, and change in the refractive index $d n / d T$ as:

$$
\frac{d \in}{d T}=n \alpha+\frac{d n}{d T}
$$

Typical value of $n, \alpha$, and $d n / d T$ are $1.4,4 \times 10^{-7}$, and $10^{-5}$, respectively, which means that $d n / d T$ is the dominant term. $d \in / d T$ has been measured $\sim 10^{-5}$ in laboratory experiments (Hocker 1979; Zumberge et al. 2018). We note that the real coefficient may be small in the ocean-bottom environment, as estimated by Zumberge et al. (2018), such that the degree of the temperature change described below may up to 3-5 times larger. Nevertheless, we assume $d n / d T=10^{-5}$ in our calculations, which converts the apparent strain rate changes of 1 and 10 microstrain to 0.1 and $1 \mathrm{~K}$ temperature changes for the basin (channels 1000-4000) and ridge (channels 4000-8000) sections, respectively.
Therefore, we can regard our DAS record as distributed temperature sensing (DTS) record, though the absolute values are unknown and the relative values are only approximately measured. DTS often uses Brillouin and Raman scattering and has been applied in various fields (e.g.,Hartog 2017; Miah and Potter 2017; Lu et al. 2019). Sinnett et al. (2020) demonstrated the usefulness of DTS in oceanographic researches, by measuring temperature fields along several ocean bottom cables at shallow $(<100 \mathrm{~m})$ depth. They detected tidally modulated spatiotemporal temperature variations up to about 6 degrees, which migrate along the fiber. Rapid increase and relatively slow and more random decrease of temperature are characteristics commonly observed in their DTS record and our DAS record.

Our record suggests temporal temperature variation up to several degrees, given the abovementioned conversion is correct. Temperature variations of $\sim 0.2 \mathrm{~K}$ were measured by the temperature sensors of the oceanbottom pressure gauges along the Muroto cable (Inazu and Hino 2011), which is comparable with our observations in the basin section. However, we are unaware of any direct measurements of ocean-bottom temperature changes that are as large as several degrees. For example, Petruncio et al. (1998) reported large diurnal temperature change at a depth of $370 \mathrm{~km}$ in Monterey Canyon, USA, but the amplitude is usually less than $1 \mathrm{~K}$. Conductivity-temperature-depth measurements have suggested large standard deviations in the water temperature of up to several degrees at several locations near our cable in the Nankai subduction zone (Watanabe and Uchida 2016). The variations at $<800 \mathrm{~m}$ depth are particularly large and likely due to the effect of the Kuroshio Current; our observations are likely related to such large variations. Nevertheless, the large uncertainty remains in our amplitude conversion, which may be modified in future calibration studies.

These temperature variations must reflect the movement of ocean water, with the rapid changes also suggesting movement at a sharp boundary, or interface, between two water masses with different temperatures. Internal surface waves are excited by tidal current and propagate on the interface much faster than the current itself. Complicated shape of the wave front especially during the increase of temperature suggests the breakage of the wave fronts and local water mixing. Although tidal modulation likely has a major influence on this movement, the effect of the Kuroshio Current, a strong surface ocean current that flows from west to east at $>1 \mathrm{~m} / \mathrm{s}$ across the study region, may not be negligible. The overall orientation of the cable is at a large angle relative to the mean direction of the Kuroshio Current, such that the influence 
of this current on the DAS observations may be reduced. Nevertheless, the current direction near the ocean bottom might be different due to the complex bathymetry of the region, including Muroto Basin and Tosabae Ridge, which forms a narrow saddleback structure along the cable. Therefore, the ocean-bottom water mass likely moves as a result of complex interactions between relative steady ocean currents and quasi-periodic oceanic tides that are bounded by an irregular bathymetry. It should be noted that the migration velocity of $10 \mathrm{~km} / 6 \mathrm{~h}$ $(\sim 0.5 \mathrm{~m} / \mathrm{s})$ is only the apparent velocity along the cable orientation, such that the speed of two- or three-dimensional boundaries can be much slower and yield a similar apparent migration velocity. Nevertheless, this rapid, long-distance migration suggests the existence of relatively large-scale movement near the deep $(\sim 1000 \mathrm{~m})$ ocean bottom at a velocity comparable with the Kuroshio Current at the surface. This observation may prove useful in advancing our understanding of the mechanisms that drive the tidal mixing of deep ocean water.

\section{Discussion and conclusion}

We demonstrate that DAS can observe a suite of geophysical signals via DAS observations from an unused seafloor fiber-optic cable offshore Cape Muroto over a 5 -day period. Our original interest was broadband seismic signals since the measured quantity is supposed to be the axial strain of the cable. We show that the performance of high-frequency $(>1 \mathrm{~Hz})$ seismic observations is almost comparable with those of ocean-bottom permanent seismic stations, as long as the cable is well-coupled with the ocean bottom. Although only one component of the strain is measurable, high-density DAS observations at many channels could prove useful for quantifying different aspects of the local seismic structure and seismic source parameters.

The Nankai subduction zone is well known for various slow earthquake activity. Although our temporary observations did not detect any tectonic tremor or lowfrequency earthquakes, which generally yields signals above $1 \mathrm{~Hz}$, the noise level suggests that the cable has the ability to detect these phenomena if they occur within a few tens of kilometers of the cable. However, in the frequency range for very low frequency earthquakes, i.e., $0.02-0.05 \mathrm{~Hz}$, the DAS observations are noisier than the short-period sensors, which makes such event detection impossible unless they occur very close to the cable.

The major noise source for the DAS measurements is the noise due to temperature-dependent changes in the refractive index; this effect is particularly large at very low frequencies. The amplitude of the temperature-dependent noise is as much as 10 microstrain for quasi-static ( $>5 \mathrm{~min}$ ) observations, which is about two orders of magnitude larger than expected for earth and ocean tide signals. However, this temperature-dependent noise can be used as a signal to monitor the temperature field, i.e., as DTS observation. Although DAS observation lacks the information of absolute temperature, it is relatively easy to detect systematic variations in space and time, as observed in our experiment. This strain-totemperature conversion is only possible via continuous spatiotemporal monitoring, such as DAS observations. We can identify several migration sequences of rapid temperature changes that are up to several degrees, some of which propagated more than $10 \mathrm{~km}$ over several hours. We believe that this is the first report of such oceanbottom temperature migration events. These events likely arise from interactions between the periodic tides, complex bathymetry, and strong Kuroshio Current, and may contribute to deep-water mixing processes near the ocean bottom.

\section{Supplementary Information}

The online version contains supplementary material available at https://doi. org/10.1186/s40623-021-01385-5.

Additional file 1: Figure $\mathbf{S 1}$. Spectrogram at 10 selected channels. This shows periodogram of strain rate calculated for every 5 minutes. Figure S2. Strain rate periodogram for each channel. Normalized for each channel. S2, M2, K1, and $\mathrm{O} 1$ show the period of four large tide constituents. (PDF $1889 \mathrm{~KB})$

\section{Abbreviations}

DAS: Distributed Acoustic Sensing; DTS: Distributed Temperature Sensing; JAMSTEC: Japan Agency for Marine Earth Science and Technology.

\section{Acknowledgements}

We thank constructive comments from an anonymous reviewer and Dr. Zack Spica. We used The Generic Mapping Tool (Wessel et al. 2013) to prepare figures.

\section{Authors' information}

S.I. is a professor in Department of Earth and Planetary Science, The University of Tokyo. E.A. and H.M. are senior researcher and researcher in Japan Agency for Marine Earth Science and Technology.

\section{Authors' contributions}

S.I. analyzed DAS data and wrote most of the manuscript. E.A and H.M. carried out DAS observation. E.A. pointed out the importance of temperature. All authors contributed to finalize the manuscript.

\section{Funding}

This research was supported by JSPS Kakenhi (16H02219), MEXT Kakenhi (16H06477), and the Earthquake and Volcano Hazards Observation and Research Program of MEXT.

Availability of data and materials

All data necessary to make figures will be provided upon the request to the authors.

Ethics approval and consent to participate

Not applicable. 


\section{Consent for publication}

Not applicable.

\section{Competing interests}

We have no financial and non-financial competing interests.

\section{Author details}

1 Department of Earth and Planetary Science, The University of Tokyo, 7-3-1, Hongo, Bunkyo, Tokyo 113-0033, Japan. ${ }^{2}$ Japan Agency for Marine Earth Science and Technology, 2-15, Natsushima, Yokosuka, Kanagawa 237-0061, Japan.

Received: 30 November 2020 Accepted: 19 February 2021

Published online: 04 March 2021

\section{References}

Ajo-Franklin JB, Dou S, Lindsey NJ, Monga I, Tracy C, Robertson M, Tribaldos VR, Ulrich C, Freifeld B, Daley T, Li X (2019) Distributed acoustic sensing using dark fiber for near-surface characterization and broadband seismic event detection. Sci Rep 9:1328. https://doi.org/10.1038/s41598-018-36675-8

Araki E, Shinohara M, Sacks S, Linde A, Kanazawa T, Shiobara H, Mikada H, Suyehiro K (2004) Improvement of seismic observation in the ocean by use of seafloor boreholes. Bull Seismol Soc Am 94:678-690

Benioff H (1935) A linear strain seismograph. Bull Seismol Soc Am 25:283-309

Beroza GC, Ide S (2011) Slow earthquakes and nonvolcanic tremor. Annu Rev Earth Planet Sci 39:271-296. https://doi.org/10.1146/annurev-earth -040809-152531

Hartog A (2017) An introduction to distributed optical fibre sensors. CRC Press, Boca Raton, FL

Hocker GB (1979) Fiber-optic sensing of pressure and temperature. Appl Opt 18:1445-1448

Inazu D, Hino R (2011) Temperature correction and usefulness of ocean bottom pressure data from cabled seafloor observatories around Japan for analyses of tsunamis, ocean tides, and low-frequency geophysical phenomena. Earth Planet Space 63:1133-1149. https://doi.org/10.5047/ eps.2011.07.014

Lindsey NJ, Martin ER, Dreger DS, Freifeld B, Cole S, James SR, Biondi BL, Ajo-Franklin JB (2017) Fiber-optic network observations of earthquake wavefields. Geophys Res Lett 44:11-792. https://doi.org/10.1002/2017G L075722

Lindsey NJ, Rademacher H, Ajo-Franklin JB (2020) On the broadband instrument response of fiber-optic DAS arrays. J Geophys Res Solid Earth 125:e2019JB018145. https://doi.org/10.1029/2019JB018145

Lu P, Lalam N, Badar M, Liu B, Chorpening BT, Buric MP, Ohodnicki PR (2019) Distributed optical fiber sensing: review and perspective. Appl Phys Rev 6:041302. https://doi.org/10.1063/1.5113955

Miah K, Potter DK (2017) A review of hybrid fiber-optic distributed simultaneous vibration and temperature sensing technology and its geophysical applications. Sensors 17:2511. https://doi.org/10.3390/s17112511

Momma, H. Fujiwara, N., Kawaguchi,m K., Iwase, R., Suzuki, S., Kinoshita, H (1997) Monitoring system for submarine earthquakes and deep sea environment. Proc. MTS/IEEE OCEANS '97 2:1453-1459.

Obara K, Kato A (2016) Connecting slow earthquakes to huge earthquakes. Science 353:253-257. https://doi.org/10.1126/science.aaf1512
Peterson, J. (1993) Observations and modeling of seismic background noise. US Geological Survey Open-File Report 93-322.

Petruncio ET, Rosenfeld LK, Padaun JD (1998) Observations of the internal tide in Monrerey Canyon. J Phys Oceanogr 28:1873-1903. https://doi. org/10.1175/1520-0485(1998)028\%3c1873:OOTITI\%3e2.0.CO;2

Shinohara M, Yamada T, Akuhara T, Mochizuki K, Sakai S, Hamakawa M, Kasajima T, Arioka T, Kubota S (2019) Distributed Acoustic Sensing measurement by using seafloor optical fiber cable system off Sanriku for seismic observation. In OCEANS 2019 MTS/IEEE SEATTLE (pp. 1-4). Seattle, WA: IEEE. Doi:https://doi.org/10.23919/OCEANS40490.2019.8962757

Sinnett G, Davis KA, Lucas AJ, Giddings SN, Reid E, Harvey ME, Stokes I (2020) Distributed temperature sensing for oceanographic applications. J Atmos Ocean Technol 37:1987. https://doi.org/10.1175/JTECH-D-20-0066.1

Sladen A, Rivet D, Ampuero JP, De Barros L, Hello Y, Calbris G, Lamare P (2019) Distributed sensing of earthquakes and ocean-solid Earth interactions on seafloor telecom cables. Nat Commun 10:1-8. https://doi.org/10.1038/ s41467-019-13793-Z

Spica ZJ, Perton M, Martin ER, Beroza GC, Biondi B (2020a) Urban seismic site characterization by fiber-optic seismology. J Geophys Res Solid Earth 125:e2019JB018656. https://doi.org/10.1029/2019JB018656

Spica ZJ, Nishida K, Akuhara T, Pétrélis F, Shinohara M, Yamada T (2020b) Marine sediment characterized by ocean-bottom fiber-optic seismology. Geophys Res Lett 47:e2020GL088360. https://doi.org/10.1029/2020G L088360

Suetsugu D, Shiobara H (2014) Broadband ocean-bottom seismology. Annu Rev Earth Planet Sci 42:27-43. https://doi.org/10.1146/annurev-earth -060313-054818

Wang HF, Zeng X, Miller DE, Fratta D, Feigl KL, Thurber CH, Mellors RJ (2018) Ground motion response to an ML 4.3 earthquake using co-located distributed acoustic sensing and seismometer arrays. Geophys J Int 213:2020-2036. https://doi.org/10.1093/gji/ggy102

Watanabe S, Uchida T (2016) Stable structures of temperature and salinity validated by the repeated measurements in the few-miles-square regions off Japan coast in the western Pacific. Rep Hydrogr Oceanogr Res 53:57-81

Wessel P, Smith WHF, Scharroo R, Luis J, Wobbe F (2013) Generic mapping tools: improved version released. EOS Trans AGU 94:409-410. https://doi. org/10.1002/2013EO450001

Williams EF, Fernández-Ruiz MR, Magalhaes R, Vanthillo R, Zhan Z, GonzálezHerráez M, Martins HF (2019) Distributed sensing of microseisms and teleseisms with submarine dark fibers. Nat Commun 10:1-11. https://doi. org/10.1038/s41467-019-13262-7

Yu C, Zhan Z, Lindsey NJ, Ajo-Franklin JB, Robertson M (2019) The potential of das in teleseismic studies: Insights from the Goldstone experiment. Geophys Res Lett 46:1320-1328. https://doi.org/10.1029/2018GL081195

Zhan Z (2020) Distributed acoustic sensing turns fiber-optic cables into sensitive seismic antennas. Seismol Res Lett 91:1-15. https://doi. org/10.1785/0220190112

Zumberge MA, Hatfield W, Wyatt FK (2018) Measuring seafloor strain with an optical fiber interferometer. Earth Space Sci 5:71-379. https://doi. org/10.1029/2018EA000418

\section{Publisher's Note}

Springer Nature remains neutral with regard to jurisdictional claims in published maps and institutional affiliations. 